tiveness. Above all, it stresses the need for flexible learning pathways that enable all students, from all backgrounds and ages, to move through the educational system throughout their lifetimes. Accepting that educational providers, public and private, are part of a "coordinated system," rather than individualistic self-serving institutions, is in itself an important statement. Finally, by its swift endorsement of the report's principles and recommendations, the Welsh government conspicuously diverged from the market-demand driven approach adopted by the UK government for England.

DOI: http://dx.doi.org/ıo.6oI7/ihe.20I8.92.I022I

\section{English-medium Instruction and the Information Tech- nology Parallel in Japanese Higher Education}

\section{An nette Bradford and Howard Brown}

Annette Bradford is associate professor, School of Business Administration, Meiji University, Tokyo, Japan. E-mail: bradford@meiji.ac.jp. Howard Brown is associate professor, Faculty of International Studies and Regional Development, University of Niigata Prefecture, Niigata, Japan.E-mail: brown@unii.ac.jp.

Tn Japan, as in much of the world, English-medium in1 struction (EMI) is part of an effort to internationalize the higher education sector, attract international students, and foster global competencies among students. It is receiving significant government investment and attention, and consequently assuming, perhaps not a central, but a meaningful role in higher education. However, the growth of EMI has not been without challenges and these are not unique to current internationalization efforts. It may be that we are seeing the most recent manifestation of longstanding structural issues in the Japanese higher education sector. When information technology (IT) was promoted in education in the I990s, bureaucratic procedures, lack of technical support, and resistance to emerging pedagogies were found to be impediments to effective implementation. For anyone involved in current EMI implementation, these obstacles ring familiar. The parallels are striking and, by looking at the example of IT, we may catch a glimpse of where EMI is heading and learn where structural changes could be made.

\section{Striking Parallels}

The first parallel is related to the context of implementation. During the IT revolution, innovation was driven by a sense of crisis, a feeling that Japan had fallen behind in the race to adopt IT and urgently needed to catch up. There was a demand from potential employers for graduates with IT skills who possessed originality, individuality, creativity, initiative, and leadership abilities. Today Japan faces challenges from a globalizing society, a stagnant economy, and demographic changes; the rhetoric of crisis is again clear. The demand from business now is for more globally competent human resources: young people who have strong communication skills, understand different cultures and values, work creatively, take independent action, and can become global leaders.

Another aspect is seen in how implementation is approached at the national level. When IT was introduced, competitive grants funded initial large-scale implementation, with most resources going to elite universities. Less prestigious universities adopted IT later and on a smaller scale, without a clear mandate or coordinated strategy. The same is seen today with the national Global 30 and Top Global funding schemes supporting EMI initiatives at a small number of prestigious universities, while most EMI programs develop without government support or a central plan.

A third parallel emerges at the institutional level. Early IT initiatives were largely volunteer based and faculty led. Administrators assigned to IT projects were mainly generalists; there was a serious lack of skilled IT personnel. With this limited support, faculty leaders had to transform themselves into IT specialists. The same dynamics can be seen today. Internationalization activities and EMI programs are supported by nonspecialist administrators, many assigned to the EMI program for a limited term. Most of the leadership for EMI is coming from faculty members who, until they began working on EMI implementation, had no experience with, and limited knowledge of, EMI. Over the last Io years, they have trained themselves to become specialists.

A fourth element concerns a focus on implementation rather than integration. In the case of IT, at the institutional level it was much more important to ensure the availability of a certain number of computers than to consider how those computers would be used to facilitate learning and teaching. Even now, a full two decades after the rush to implement IT, the infrastructure is in place, but Japan lags behind other countries in the actual educational adoption of IT. Equipment and software are widely available in universities, but little attention has been given to training or the development of pedagogy to support its usage. Similarly, much EMI implementation is characterized by decision- 
making based on simplistic assumptions, a focus on numbers of EMI classes and student mobility rates, and ad hoc delivery. Coherent curriculum development, the linguistic, social, and academic needs of students, and the profession al development of faculty members are not receiving the attention they deserve.

A final, and perhaps overarching parallel between IT and EMI can be seen in how both have been going against a prevailing social structure. IT was seen as an addition. It was a layer added to existing administrative and curricular precedents, rather than an impetus for deep structural change within universities or the wider social environment. The attempt to develop a new generation of computer-literate specialist students went against the notion of what universities were supposed to do at the undergraduate level: produce generalists. This struggle is familiar to those work-

\section{Another aspect is seen in how imple- mentation is approached at the national level.}

ing in current EMI initiatives. EMI is being implemented, in many cases, to create an internationally minded young generation. However, this goal runs counter to the prevailing notion of the importance of Japanese national identity. The ministry of education has repeatedly emphasized that moral education, and a deep understanding of Japanese traditions and culture, are prerequisites for global education. This leads to attempts to foster students as outward-looking people, but not too outward looking. The deep and possibly identity-threatening changes in institutional culture, administrative structures, and pedagogical approaches necessary to make EMI a central part of Japanese higher education are slow to be adopted.

\section{THE WAY ForWARD}

Looking back at the IT experience, the key roadblocks to implementation stemmed from decisions that universities made when they set out to establish new systems and policies. Implementing IT and effectively integrating it university-wide would have meant making deep systemic changes in the culture and politics of the given institution, a daunting prospect. The alternative, focusing on superficial technical issues and numerical targets on a department-bydepartment basis, thereby avoiding the more troubling issues, was an easier path. Universities chose the easier path. Implementation was characterized by short-term planning and reactive problem solving. Consequently, IT has never really lived up to its potential in higher education. Communications technology, information management, and online distance education all remain relatively underdeveloped in Japanese universities.

But what of current EMI initiatives? All signs indicate that we are heading down the same easy path of short-term, reactive decision-making. In 20 years, EMI could be where IT is now, with a stable position as a commonplace part of higher education, but not playing a central role and not deeply integrated into the university culture. If that is what we, as EMI stakeholders, want, then we may be on the right path. However, EMI in Japan is still in its infancy and there is time for universities to take a more challenging path. When properly integrated, EMI has the potential to effect the internationalization of Japanese higher education. We can learn from the experience of the IT programs before us and consider the structural changes that need to take place to ensure not just successful EMI implementation, but real EMI integration.

DOI: http://dx.doi.org/ıo.6oI7/ihe.20I8.92.9810

\section{Admissions in Japanese National Universities: The Need for Change}

\section{YUKIKO ISHIKURA AND TATSUO KaWASHIMA}

Yukiko Ishikura is lecturer and Tatsuo Kawashima is professor and director of the Center for the Study of Higher Education and Global Admissions (CHEGA), Osaka University, Japan. E-mails: ishikura@ chega.osaka-u.ac.jp and tatsu0314@chega.osaka-u.ac.jp.

Tapanese college admissions at national universities have traditionally practiced a devolved selection process. Faculty members in each department design their own admissions policies and criteria, and make selection decisions. There are admissions offices, but their responsibilities tend to be mostly administrative and managerial.

Up until this point, written examinations have been the most valued selection criteria at national universities. The majority of applicants to national universities are required to take two written examinations: a multiple-choice national examination called "National Center Test for University Admissions" (hereafter National Center Test), administered once annually in early January, and a second-stage examination administered by each university after the National 